\title{
Student Engagement in a Gamified Physics Course
}

\author{
Coleen M. Amado and Lydia S. Roleda \\ De La Salle University, Philippines
}

\begin{abstract}
This study investigated the undergraduate students' behavioral, emotional, and cognitive engagement in a gamified Physics course. The participants in the study are engineering students from a state university in Manila, Philippines taking up a summer class in Electromagnetics. The course was gamified by incorporating various games elements which include experience points (XP), leaderboard, quests, events, challenges, achievements, leaderboards, and power-ups. The engagement of students was measured using the Student Engagement Measure (SEM). Other measures such as the students' attendance and participation in various activities were also taken. The overall and the mean scores, standard deviations, and correlation coefficients per dimension were calculated. The results revealed a high level of behavioral, emotional, and cognitive engagement of students in the gamified physics course. The three subscales were also found to be significantly correlated with each other. Furthermore, the journal and interview transcripts revealed that students exhibited active participation, established good relationships with others and perceived the course to be fun, enjoyable and exciting, and exerted more effort and work beyond what is required in the gamified course.
\end{abstract}

Keywords: gamification, student engagement, physics, behavioral engagement, cognitive engagement, emotional engagement

\section{Introduction}

One of the factors that affect learning is student engagement. Literature on student engagement describes it as having multiple components and subtypes. Fredericks, Blumenfeld and Paris (2004) identified three dimensions of student engagement: behavioral, emotional and cognitive. Behavioral engagement is a measure of attention, attendance, time on homework, preparation and participation in class and other school-based activities, concentration, and adherence to classroom rules. Emotional engagement, on the other hand, refers to emotional reactions to class or school and quality of relationships with peers and instructors which affects willingness to work. Lastly, cognitive engagement is a measure of cognitive strategy use, effort exerted in doing work and working beyond the requirements of the school.

Various researches on the relationship between student engagement and learning reveal that engagement is a predictor of academic achievement (Wara, Aloka, Odongo, 2018; Gunuc, 2014) and a factor in students' perseverance in continuing to the next level of their education (Kuh, Cruce, Shoup, \& Kinzie, 2008). In addition, engagement was also found to lead towards enhancement on students' critical thinking and use of deep learning approaches (Pike and Kuh, 2005). On the other hand, poor engagement results into low performance in school (Huang and Soman, 2013) disengagement leads to increased dropout rate, problems on behavior, and academic performance of students (Fredricks, et. al., 2004).

Engaging students in school is a challenge faced by educators across countries. A survey conducted by Gallup, found that only half of adolescents in the United States report feeling engaged in school, and a fifth are actively disengaged. About ten percent of students are classified as both disengaged and discouraged (Brenneman, 2016). This is consistent with the 2003 National Research Council report on motivation which revealed that forty percent of high school students are chronically disengaged from school (Crotty, 2013). Moreover, boredom is identified as one of the reasons for students dropping out of school. The students pointed out that 
they don't find the academic content interesting anymore and that they feel that they don't have a personal connection with their teachers (Willis, 2010).

In the Philippines, on the other hand, almost ten percent of the estimated 39 million Filipinos 6 to 24 years old were out-of-school children and youth, according to the results of the 2016 Annual Poverty Indicators Survey (APIS). One of the identified reasons, which accounts to $19.7 \%$, is the lack of personal interest (Philippine Statistics Authority, 2017). Similarly, a research conducted on UNICEF children also revealed lack of interest as the primary factor as to why students are not in school (Orbeta, 2005).

To address the problems on disengagement of students, researchers have been continuously looking for ways to improve student engagement in school, hence, they took interest on the incorporation of games in the classroom. Games have been found to be effective in promoting learning (Anetta, Minogue, Holmes \& Cheng, 2009; Van Eck, 2006) and enhancing engagement and motivation (Griffiths and de Freitas, 2007; Barab, Thomas, Dodge, Carteaux, Tuzun, 2005). However, educators faced a difficulty in finding games that will match the curriculum (Tuzun, 2007) and will fit the restrictions of classroom delivery (Gros, 2007). Hence, the concept of gamification was formulated.

Gamification is creating a game-like environment in non-game contexts with the use of various game elements (Deterding, Dixon, Khaled, \& Nacke, 2011). The most common game elements used are experience points, levels, leaderboards, and badges (Lister, 2015). Researches on the use of gamification reveal both positive and negative effects on student engagement. In the study conducted by Gasland (2011), students find a point-based system motivating and engaging. On the contrary, the study of Meyer (2008) revealed that the use of points does not actually improve the quality of students' outputs. On the other hand, Goehle (2013) found that the use of levels in a gamified classroom led students to actively work because they were able to keep track of their progress and that the badges and achievements made students feel rewarded and acknowledged for their efforts. However, Haaranen, Ihantola, Hakulinen, and Korhonen (2014) and Hanus and Fox (2015) found out that the badges and leaderboards were demotivating for the students.

Given the mixed results on the effect of gamification on student engagement, the current study aimed to contribute to the existing literature through investigating on the students' behavioral, emotional, and cognitive engagement in a gamified physics course. Specifically, this research sought to answer the following questions: (1) What are the levels of the students' behavioral, emotional, cognitive engagement in a gamified physics course?; (2) How are the behavioral, emotional, and cognitive engagement of the students in a gamified physics course related?; and (3) What are the students' experiences in a gamified physics course?

The study was envisioned to help the educators address problems on poor engagement of students by incorporating gamification in their instruction, specifically for the tertiary level. Most of the undergraduate courses are taught using the traditional way, without much consideration on the students' motivation and interest. Furthermore, this was intended to contribute to the literature by shedding light on the effects of gamified instruction since previous researches reveal both positive and negative effects to the students.

\section{Method}

To gamify the Electromagnetics course, instructional materials were designed to have a game-like interface. The exercises, homework and quizzes were in the form of quests and challenges and corresponding scores were given in the form of experience points (XP). To provide the students a choice as to what activities to take part in, just like when playing actual games, the events, which are questions posted online, were made optional for the students. To incorporate the element of competition in the class, on the other hand, a leaderboard, which displayed the ranking of the students according to their acquired experience points, was also included as part of the gamified course. In the leaderboard, the students are represented by their avatar and codename so that their identity will be unknown to the other members of the class. Aside from the experience points, the students were 
also awarded achievements, from which they can get coins to purchase power-ups, and badges, when they meet certain conditions.

The study employed a mixed method descriptive research design. At the end of the course, the students were asked to answer the School Engagement Measure (SEM) developed by Dr. Phyllis Blumenfeld and Dr. Jennifer Fredricks, to measure their behavioral, emotional, and cognitive engagement in the gamified course. The instrument consisted of fifteen (15) items to be rated using a 5-point Likert scale. The mean scores per subscale and the overall mean scores and standard deviations were calculated to describe the students' engagement upon experiencing a gamified physics course. To determine the relationship among the behavioral, emotional, and cognitive engagement, correlational analysis was used. Furthermore, journal and interview transcripts were coded to describe the students' experiences in the gamified course.

\section{Results and Discussion}

\section{$\underline{\text { Student Engagement in a Gamified Physics Course }}$}

Table 1 shows the mean scores and standard deviations overall and per item in the behavioral engagement subscale of the SEM after the students experienced a gamified course. For all items in the subscale, the mean scores indicate high level of behavioral engagement. The students in the gamified course pay attention to class and are on-task. The results also reveal that they adhere to the school rules and policies. Similarly, the overall mean score also suggests a high level of engagement.

Table 1 Mean scores and standard deviations overall and per item in the behavioral engagement subscale of the SEM in the gamified course

\begin{tabular}{|c|c|c|}
\hline Statement & Mean $<\mu>$ & $\begin{array}{c}\text { Standard Deviation } \\
<\text { SD }>\end{array}$ \\
\hline I pay attention in class. & 4.52 & .508 \\
\hline When I am in class, I just act as if I'm working. & 5.00 & .000 \\
\hline I follow the rules at school. & 4.45 & .506 \\
\hline I get in trouble at school. & 4.65 & .486 \\
\hline Overall & 4.65 & .375 \\
\hline
\end{tabular}

Measures of behavioral engagement also include the attendance and participation of students. Based from the records, only ten (10) students had absences ranging from only one (1) to three (3) times only. This indicates good attendance of students in the gamified physics course. Some of the identified reasons for absences are health and financial problems, both are not related in any way to disengagement. As for the students' participation, the percentage of participants for each event was also calculated (see Table 2). The high percentages, considering that events were not really required for students to answer, indicate a high level of student participation. The only reason for non-participation in the events identified by the students was the lack of access to internet connection.

The findings from the current study suggest a good attendance and high level of participation of the students in the gamfied physics course. These results are similar to that of the study of Barata, et. al (2013) which is a longitudinal study designed to measure the engagement of students in a gamified college course by incorporating experience points, levels, badges, challenges and leaderboards. The results showed significant improvements in attention, participation and proactivity. 
Table 2 Percentage of participants in the online events in a gamified physics course

\begin{tabular}{lll}
\hline Event No. & Number of Participants & Percentage of Participants \\
\hline 1 & 28 & $90 \%$ \\
\hline 2 & 30 & $97 \%$ \\
\hline 3 & 26 & $84 \%$ \\
\hline 4 & 24 & $77 \%$ \\
\hline 5 & 24 & $77 \%$ \\
\hline 6 & 25 & $81 \%$ \\
\hline 8 & 28 & $90 \%$ \\
\hline
\end{tabular}

e 3 shows the mean scores and standard deviations overall and per item in the emotional engagement subscale of the SEM. The mean scores for each item indicate that students perceive the gamified course to be fun, exciting and interesting. Likewise, the overall mean score suggests a high level of emotional engagement of the students.

Table 3 Mean scores and standard deviations overall and per item in the emotional engagement subscale of the SEM in the gamified course

\begin{tabular}{|c|c|c|}
\hline Statement & Mean $<\mu>$ & $\begin{array}{c}\text { Standard Deviation } \\
<\mathrm{SD}>\end{array}$ \\
\hline I feel happy in school. & 4.13 & .619 \\
\hline I feel bored in school. & 3.94 & .680 \\
\hline I feel excited by the work in school. & 4.29 & .529 \\
\hline I like being at school. & 4.29 & .693 \\
\hline I am interested in the work at school. & 4.32 & .475 \\
\hline My classroom is a fun place to be. & 4.48 & .508 \\
\hline 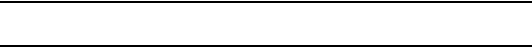 & 4.24 & .584 \\
\hline
\end{tabular}

Table 4 shows the mean scores and standard deviations overall and per item in the cognitive engagement subscale of the SEM. The results for each item in the subscale suggest that students made use of cognitive strategies such as reflections and engage in extra work such as doing advanced study, even when there are no examinations coming up. This suggest a high level of cognitive engagement which is also reflected in the overall mean score for this subscale.

Table 4 Mean scores and standard deviations overall and per item in the cognitive engagement subscale of the SEM in the gamified course

\begin{tabular}{|c|c|c|}
\hline Statement & Mean $<\mu>$ & $\begin{array}{c}\text { Standard Deviation } \\
<\mathrm{SD}>\end{array}$ \\
\hline I feel happy in school. & 4.13 & .619 \\
\hline I feel bored in school. & 3.94 & .680 \\
\hline I feel excited by the work in school. & 4.29 & .529 \\
\hline I like being at school. & 4.29 & .693 \\
\hline I am interested in the work at school. & 4.32 & .475 \\
\hline My classroom is a fun place to be. & 4.48 & .508 \\
\hline Overall & 4.24 & .584 \\
\hline
\end{tabular}


The Relationship of the Students' Behavioral, Emotional, and Cognitive Engagement in a Gamified Physics $\underline{\text { Course }}$

Mean scores and standard deviations overall and per item in the behavioral engagement subscale of the SEM in the gamified course

\begin{tabular}{lccc}
\hline \multicolumn{1}{c}{ Subscale } & Behavioral & Emotional & Cognitive \\
\hline Behavioral & 1 & $.468^{* *}$ & $.635^{* *}$ \\
\hline Emotional & $.468^{* *}$ & 1 & $.522^{* *}$ \\
\hline Cognitive & $.635^{* *}$ & $.522^{* *}$ & 1 \\
\hline$* * p<0.01$ & & &
\end{tabular}

Table 5 shows the correlation coefficients for the relationship among the students' behavioral, emotional and cognitive engagement in a gamified physics course. The results indicate that there is a significant moderate positive correlation between the behavioral and emotional engagement and the cognitive and emotional subscales while there is a strong positive correlation between behavioral and cognitive engagement. These suggest that when one dimension of engagement is at high level, the others are also at a high level. Hence, enhancing one dimension of the students' engagement may lead to the improvement of the other dimensions as well.

\section{Students' Experiences in a Gamified Physics Course}

In the journal and the interview, the students were asked to describe their experiences in the gamified physics course, focusing on their behavioral, emotional and cognitive engagement. The transcripts revealed the following results:

\section{The students participate more actively, pay more attention and are focused in class.}

The accounts of the students indicate that the students were participating in the gamified course, not only those who are actively participating through recitation and board work but also those who are just listening and taking down notes. This shows that the students are focused and pay attention to what is transpiring in the classroom.

Students: "We participate more in this class because all of us are given a chance to answer."

Student 2: "While in class, I was just quiet there, listening, understanding the lectures, and taking down notes [on topics] that seem difficult to me."

Student 5: "I take down notes and listen eagerly."

Student 6: "In our class today, the ambiance is really different. You can see that my classmates are all participating, listening, and interested in the discussion."

The study of Anderson, Huttenlocher, Kleinberg, \& Leskovec, 2013 revealed similar results. In this study, the researchers investigated how badges can influence and steer user behavior on a site and the results revealed an increase in site participation. In addition, the findings from the study of Denny (2013) also showed a positive impact of incorporating a badge-based achievement system in an online learning tool on the level and quality of participation. 


\section{The students formed positive relationships with their classmates and the instructor.}

The students were able to establish positive relationships with their classmates and the instructor. The students were able to form bonds with their classmates and build good rapport with the instructor. This gave the student an avenue for consultation, especially when they have difficulties in the subject. Instead of figuring out these difficulties alone, the students are helping each other. There's also a friendly competition that exists in the classroom.

Student 13: "As time passed by, my classmates and I became closer together. This helps us learn the lesson without having hard time."

Student 15: "The teacher is approachable. And when you didn't get a part of the lecture, you can ask."

Student 24: "It's fun. There's competition but we're friends. We're always laughing."

Student 25: “We help each other. When you don't understand something or you're confused, you can ask someone then it will be explained to you."

3. The students experienced both positive feelings of fun, excitement, and ease, and negative feelings of anxiety, stress and frustration.

Though the students mostly experienced positive emotions of fun, excitement and ease while they are engaged in the gamified course, because of the set-up and the grading system of acquiring experience points instead of scores, some students also expressed feelings of stress, anxiety and disappointment. These negative emotions were brought by the pressure to gain experience points. Since the leaderboard is part of the design of the gamified course, the students get to monitor their progress and get to compare it with that of others, unlike in the set-up in a regular classroom. Hence, when they see that they're not doing well in the rankings, they become frustrated and stressed out, which is normal, given the competitive nature of individuals. Despite these negative emotions, students still benefit for these give them the drive to perform better every time.

Student 2: "We don't feel pressured in the class, it's fun and we enjoy the class."

Student 16: "The class is enjoyable and exciting because of the way of teaching and providing materials that makes the subject easy to understand."

Student 21: "As days go by, we do not have any grade conscious mentality in my opinion because it seems we are just enjoying the subject."

Student 5: "I'm nervous about not getting XP for a day and not making it to the top half of the leaderboard."

Student 24: "Today we received our already checked boss battle and I feel bad with my scores."

Student 30: "Unfortunately, I have a bad standing on our leaderboard. I got sad and hopeless. Bottom two is so much stressful. I don't know how I'll get to the top again. I am very disappointed with myself right now."

In the current study, the students also reported feelings of fun, excitement and enjoyment in the gamified class as well as good quality relationship between students, their peers and the instructor. These findings are similar to that of the studies of Cheong, Cheong and Filippou (2013) and Denny (2013) wherein the participants reported 
enjoyment and engagement from the use of multiple-choice quiz software tool and incorpartion of badges in an online learning tool, respectively. Similarly, the results from the study of Dong, et. al. (2012) also revealed that participants had fun in the use of Jigsaw as a form of a discovery-based game to learn Adobe Photoshop.

\section{The students exhibited use of cognitive strategies to help them with the course.}

The students used some cognitive strategies in studying while engaged in this gamified course. In preparing for tests, they exposed themselves to a variety of sample problems, allowing them to practice and enhance their problem-solving skills. The students also reviewed the test items after the test by solving them again and checking them against a reference. They also try to re-check the answers that were provided by the instructor and verify whether there are corrections or errors in the checking process.

Student 3: "Every practice problem, I always try to solve and get the answers. If I don't know how, I'm asking my seatmate for some brief explanation until I get the correct solution and answers."

Student 10: "I make an effort to master the subject by re-reading the topic and some of the problems in the reference book."

Student 24: "When I got home, I double checked my challenges and discovered that I got three wrong answers. I tried to solve it again using the concept and the formula."

\section{The students exerted extra effort and worked beyond what is required by the course.}

The students in the gamified physics course exerted a lot of effort and did extra work. The students reported that they study hard, practiced and reviewed for the test and they made an effort to master the topics. Furthermore, not all the items in the challenges were required for the students to answer. This is to give the students a choice on what activities or tasks they would like to engaged in. But as reported by the instructor, the students accomplished work more than what is required of them.

Student 18: "I took seriously the challenges given to us because as much as possible, I want to get all the included experience points in the challenges. I tried to answer it whenever I'm free and I did it. I finished it ahead of time."

Student 21: I can say that I've put effort on studying the subject by advanced reading, looking at my old notes, and solving some problems regarding the topic that will be discussed.

Instructor: Most of the students also submitted the challenges for chapter 1. Even though only two out of the four challenges are required, most of the students answered all of the items.

The students in the current study also reported an increase in the effort they exert in class and engaging in doing extra work. Similar findings were found by Hanus and Fox (2014) in which the student effort increased significantly over time in the gamified course.

\section{Conclusion}

This study investigated on the students' behavioral, emotional, and cognitive engagement in a gamified physics course. The results reveal that students have a high level of behavioral, emotional, and cognitive engagement. The students exhibited active participation, both in-class and online, and were focused and paying attention in class. They also formed good relationships with their classmates and the instructors and reported a positive classroom environment. They perceived the gamified course to be fun, enjoying and exciting. However, they also experienced negative emotions such as anxiety, stress, and frustration, mainly due to their standing in the leaderboard. Nonetheless, these negative emotions contributed to their drive to always perform better. Lastly, 
the students made use of cognitive strategies of practicing, reflection and verification while they are engaged in the gamified course. They also exerted more effort and did more than what is required by the course. Overall, the gamified physics course resulted into a high level of engagement and positive experience of the students.

At present, it is really a challenge for educators to get the students to be interested in their subjects, especially for highly technical subjects like math and physics. And we know that when students are not interested, they tend to not pay attention, they don't participate and they exert less effort in the different class activities, which in turn, lead to poor performance. Hence, the results of this study suggest that educators should consider the use of gamification in their classrooms to enhance students' behavioral and cognitive engagement, and hence, help improve their academic performance. Furthermore, the use of gamification also makes the instruction fun, exciting and interesting, and it fosters cooperation and healthy competition among the students which also are also important things to be considered by educators in ensuring that students will learn more effectively and efficiently. Lastly, educators might think that in the age of college students, they do not need to factor in the motivation and engagement of students in their instruction but the results of the study suggest that it still pays off to ensure that the students are engaged in the class.

This study has various limitations which can further be improved by future researchers. Other researchers can employ an experimental design to measure the effect of using a gamified instruction. For the measure of student engagement, researchers can also look into the use of another instrument which more comprehensively captures each type of student engagement. Furthermore, class observations can also be done to provide additional data for the gamified class experience of students. Lastly, other researchers could look into the effect of individual game elements since in this study, the game elements are used in combination with other elements.

\section{Acknowledgements}

The authors would like to thank the Department of Science and Technology Science Education Institute for the support in this research endeavor, specifically on its conduct and its dissemination in the Future of Education Conference 2019.

\section{References}

Anderson, A., Huttenlocher, D., Kleinberg, J., \& Leskovec, J. (2014). Engaging with massive online courses. 23rd International Conference on World Wide Web, Seoul, Korea: ACM, 687-689.

Annetta, L. A., Minogue, J., Holmes, S. Y., \& Cheng, M.-T. (2009). Investigating the impact of video games on high school students' engagement and learning about genetics. Computers \& Education, 74-85.

Barab, S., Thomas, M., Dodge, T., Carteaux, R., \& Tuzun, H. (2005). Making Learning Fun: Quest Atlantis, A Game Without Guns. ETR\&D, 86-107.

Brenneman, R. (2016, March 22). Gallup Student Poll Finds Engagement in School Dropping by Grade Level. Date of Access: 06/20/19. https://www.edweek.org/ew/articles/2016/03/23/gallup-student-poll-findsengagement-in-school.html

Cheong, C., Cheong, F., \& Filippou, J. (2013). 'Quick quiz: A gamified approach for enhancing learning'. In Jae-Nam Lee, Ji-Ye Mao, and James Thong (ed.) Pacific Asia Conference on Information Systems, 1-14.

Crotty, J. (2013, March 13). Motivation Matters: 40\% Of High School Students Chronically Disengaged From School. Date of Access: 06/20/19. https://www.forbes.com/sites/jamesmarshallcrotty/2013/03/13/motivationmatters-40-of-high-school-students-chronically-disengaged-from-school/\#3a85370a6594

Denny, P. (2013). The effect of virtual achievements on student engagement. Conference Proceedings of the SIGCHI Conference on Human Factors in Computing Systems. doi: 10.1145/2470654.2470763 
Dong, T., Dontcheva, M., Joseph, D., Karahalios, K., Newman, M. W., \& Ackerman, M. S. (2012). Discoverybased games for learning software. In Proceedings of the 2012 ACM annual conference on Human Factors in Computing Systems, 2083-2086.

Deterding, S., Dixon, D., Khaled, R., \& Nacke, L. (2011). From Game Design Elements to Gamefulness: Defining "Gamification". Proceedings of the 15th International Academic MindTrek Conference, 9-15.

Fredericks, J. A., Blumenfeld, P. C., \& Paris, A. H. (2004). School Engagement Potential of the Concept, State of the Evidence. Review of Educational Research, 74(1), 59-109. doi: 10.3102/00346543074001059

Gasland, M. M. (2011). Game Mechanic based E-Learning. Science and Technology Master Thesis. Norwegian University of Science and Technology.

Goehle, G. (2013). Gamification and web-based homework. PRIMUS: Problems, Resources, and Issues in Mathematics Undergraduate Studies, 23(3), 234-246. doi:10.1080/10511970.2012.736451

Griffiths, M., \& de Freitas, S. (2007). Online gaming and syntetic worlds as a medium for classroom learning. Education and Health, 74-76.

Gros, B. (2007). Digital games in education: The design of game-based learning environments. Journal of Research on Technology in Education, 23-38.

Gunuc, S. (2014). The Relationships Between Student Engagement and their Academic Achievement. International Journal on New Trends in Education and Their Implications, 5(4), 216-231.

Haaranen, L., Ihantola, P., Hakulinen, L., \& Korhonen, A. (2014). How (not) to introduce badges in online exercises. SIGCSE'14 Proceedings of the 45th ACM technical symposium on Computer science education, 33 38. doi: $\underline{10.1145 / 2538862.2538921}$

Hanus, M. \& Fox, J. (2015). Assessing the effects of gamification in the classroom: A longitudinal study on intrinsic motivation, social comparison, satisfaction, effort, and academic performance. Computers \& Education, 80(0), 152 - 161.

Huang, W. H-Y., \& Soman, D. (2013). A Practictioner's Guide to Gamification of Education. Toronto: Rotman School of Management University of Toronto.

Kuh, G.D., Cruce, T. M., Shoup, R., \& Kinzie, J. (2008). Unmasking the Effects of Student Engagement on First-Year College Grades and Persistence. The Journal of Higher Education, 79(5), 540-563. doi: 10.1353/jhe.0.0019

Lister, M. (2015). Gamification: The effect on student motivation and performance at the post-secondary level. Issues and Trends in Educational Technology, 1-22.

Meyer, K. (2008). Do rewards shape online discussions? Journal of Interactive Online Learning, 7(2), 126 138.

Orbeta, A. (2005). Number of Children and their Education in Philippine Households. Discussion paper series 2005-21, Philippine Institute for Development Studies.

Philippine Statistics Authority. (2017, June 13). One in Every Ten Filipinos Aged 6 to 24 Years is an Out of School Child and Youth. Date of Access: 06/20/19. https://psa.gov.ph/content/one-every-ten-filipinos-aged-624-years-out-school-child-and-youth

Pike, G. \& Kuh, G. (2005). A typology of student engagement for American colleges and universities. Research in Higher Education, 46(2), 185-209. doi: 10.1007/s11162-004-1599-0

Tuzun, H. (2007). Blending video games with learning: Issues and challenges with classroom implementations in the Turkish context. British Journal of Educational Technology, 465-477.

Van Eck, R. (2006). Digital Game-Based Learning: It's Not Just the Digital Natives Who Are Restless. EDUCAUSE, 17-30. 
Wara, E., Aloka, P., \& Odongo, B. (2018). Relationship between Emotional Engagement and Academic Achievement among Kenyan Secondary School Students. Academic Journal of Interdisciplinary Studies, 7(1), 107-118. doi: 0.2478/ajis-2018-0011

Willis, J. (2010, December 27). Inoculate Against Boredom: The arts in school to prevent dropping outphysically or virtually. Date of Access: 06/20/19. https://www.psychologytoday.com/intl/blog/radicalteaching/201012/inoculate-against-boredom

\section{Appendix}

Table 1 Mean scores and standard deviations overall and per item in the behavioral engagement subscale of the SEM in the gamified course

\begin{tabular}{|c|c|c|}
\hline Statement & Mean $<\mu>$ & $\begin{array}{c}\text { Standard Deviation } \\
<\mathrm{SD}>\end{array}$ \\
\hline I pay attention in class. & 4.52 & .508 \\
\hline When I am in class, I just act as if I'm working. & 5.00 & .000 \\
\hline I follow the rules at school. & 4.45 & .506 \\
\hline I get in trouble at school. & 4.65 & .486 \\
\hline Overall & 4.65 & .375 \\
\hline
\end{tabular}

Table 2 Percentage of participants in the online events in a gamified physics course

\begin{tabular}{lll}
\hline Event No. & Number of Participants & Percentage of Participants \\
\hline 1 & 28 & $90 \%$ \\
\hline 2 & 30 & $97 \%$ \\
\hline 3 & 26 & $84 \%$ \\
\hline 4 & 24 & $77 \%$ \\
\hline 5 & 24 & $77 \%$ \\
\hline 6 & 25 & $81 \%$ \\
\hline 8 & 28 & $90 \%$ \\
\hline
\end{tabular}

Table 3

Mean scores and standard deviations overall and per item in the emotional engagement subscale of the SEM in the gamified course

\begin{tabular}{|c|c|c|}
\hline Statement & Mean $<\mu>$ & $\begin{array}{c}\text { Standard Deviation } \\
<\mathrm{SD}>\end{array}$ \\
\hline I feel happy in school. & 4.13 & .619 \\
\hline I feel bored in school. & 3.94 & .680 \\
\hline I feel excited by the work in school. & 4.29 & .529 \\
\hline I like being at school. & 4.29 & .693 \\
\hline I am interested in the work at school. & 4.32 & .475 \\
\hline My classroom is a fun place to be. & 4.48 & .508 \\
\hline Overall & 4.24 & .584 \\
\hline
\end{tabular}

Table 4 Mean scores and standard deviations overall and per item in the cognitive engagement subscale of the SEM in the gamified course

\begin{tabular}{lcc}
\hline \multicolumn{1}{c}{ Statement } & Mean $<\mu>$ & $\begin{array}{c}\text { Standard Deviation } \\
\langle\text { SD }>\end{array}$ \\
\hline I feel happy in school. & 4.13 & .619 \\
\hline I feel bored in school. & 3.94 & .680 \\
\hline I feel excited by the work in school. & 4.29 & .529 \\
\hline I like being at school. & 4.29 & .693 \\
\hline
\end{tabular}


Coleen M. Amado and Lydia S. Roleda/ Student Engagement in a Gamified Physics Course ......

\begin{tabular}{lccc}
\hline I am interested in the work at school. & 4.32 & .475 \\
\hline My classroom is a fun place to be. & & 4.48 & .508 \\
\hline & Overall & 4.24 & .584 \\
\hline
\end{tabular}

Table 5 Mean scores and standard deviations overall and per item in the behavioral engagement subscale of the SEM in the gamified course

\begin{tabular}{lccc}
\hline \multicolumn{1}{c}{ Subscale } & Behavioral & Emotional & Cognitive \\
\hline Behavioral & 1 & $.468^{* *}$ & $.635^{* *}$ \\
\hline Emotional & $.468^{* *}$ & 1 & $.522^{* *}$ \\
\hline Cognitive & $.635^{* *}$ & $.522^{* *}$ & 1 \\
\hline$* * p<0.01$ & & &
\end{tabular}

